\title{
Blind and partial sight registration in Avon
}

\author{
R H B GREY,' C J BURNS-COX, ${ }^{2}$ AND A HUGHES 3
}

\begin{abstract}
From 'Bristol Eye Hospital; the ${ }^{2}$ Department of Medicine, Frenchay Hospital; and the ${ }^{3}$ Department of Epidemiology and Community Medicine, University of Bristol
\end{abstract}

SUMMARY All blind and partially sighted registration forms for the county of Avon for a two-year period were analysed, and the findings are presented. Comparisons with the national figure published by Sorsby over 20 years ago show there has been no marked change in the rates of blind registration per 100000 population with the exception of those for cataract, which show a large reduction. Diabetic registrations have remained similar, but this may represent an encouraging trend in view of the significant increase in the size of the diabetic population. Glaucoma may show some improvement in the future when time has elapsed for beta blockers and trabeculoplasty to be fully assessed. There has been an increase in the rate of registration from aging macular degeneration.

Since Sorsby published his extensive analyses of blindness in England and Wales ${ }^{12}$ there have been major advances in patient management in ophthalmology. The most notable advances include microsurgery, fluorescein angiography, and photocoagulation, but there have been many changes in the treatment of most of the major causes of blindness. Glaucoma, cataract, aging macular disease, trauma, retinal detachment, and diabetic and other forms of retinal vasculopathy are treated in ways quite different from 25 years ago. Some disorders, such as myopia and genetic defects, remain untreatable.

This study was undertaken with three objectives: (1) to find the overall blindness rates per annum in the county of Avon; (2) to evaluate the incidence and visual disability for the major ocular diseases; and (3) to see whether the incidence of blindness and partial sightedness has altered in the past 25 years since the introduction of modern ophthalmic techniques.

Precise comparison of the Avon figures with those published by Sorsby proved difficult because of the higher rate of different disorders affecting the fellow eye of registered patients (15\% for Avon as opposed to $6 \%$ for Sorsby). An analysis of the information available from the registration form for individual eyes was therefore undertaken in an attempt to define more accurately the contribution of each ocular disorder to the pool of partial or complete

Correspondence to Mr R H B Grey, Bristol Eye Hospital, Lower Maudlin Street, Bristol BS1 2LX. blindness. In addition this allowed an evaluation of the accuracy of whether blind or partial sight registration was correct according to the guidelines on the form, and also increased the reliability of the data to compare with Sorsby's figures.

\section{Material and methods}

All blind and partially sighted registration forms (BD8) during the two-year period 1 July 1984-31 June 1986 for the county of Avon were analysed. The registrations were divided into those fully blind and partially sighted (PS) according to the way in which the certificate had been completed by the examining ophthalmologist in section C.

As the category of blindness or PS depended on the status of the better eye, a re-evaluation of the visual handicap of all eyes for which information was available from the BD8 forms was undertaken. Details under section A (examination of the eyes) were assessed with regard to visual acuity and visual field loss, and all eyes were recategorised without reference to the information under section $C$. Visual acuity was classified as no perception of light (NPL), perception of light (PL), hand movements (HM), count fingers $(C F), 6 / 60,6 / 36,6 / 24,6 / 18,6 / 12,6 / 9$, or $6 / 6$. Although the guidelines on the form suggest a category of $3 / 60$ should be employed, this was rarely used by the registering ophthalmologist and therefore was not used for the re-evaluation for this study. 
Table 1 Number (percent) of registrations according to age and sex

\begin{tabular}{lccccc}
\hline \multirow{2}{*}{ Age } & \multicolumn{3}{l}{ Blind } & \multicolumn{3}{l}{ Partial sight } \\
\cline { 2 - 3 } \cline { 5 - 6 } \cline { 5 - 6 } & Male & Female & & Male & Female \\
\hline $0-4$ & $2(1 \%)$ & 0 & 0 & 0 \\
$5-14$ & $2(1 \%)$ & 1 & 0 & $1(1 \%)$ \\
$15-19$ & 0 & $2(1 \%)$ & & 0 & 0 \\
$20-29$ & $3(2 \%)$ & $6(2 \%)$ & & $2(2 \%)$ & $2(1 \%)$ \\
$30-39$ & $4(2 \%)$ & 1 & & $3(4 \%)$ & $3(2 \%)$ \\
$40-49$ & $3(2 \%)$ & $4(1 \%)$ & & $3(4 \%)$ & $5(3 \%)$ \\
$50-59$ & $5(2 \%)$ & $4(1 \%)$ & & $5(6 \%)$ & $7(4 \%)$ \\
$60-64$ & $14(3 \%)$ & $11(3 \%)$ & $6(7 \%)$ & $8(4 \%)$ \\
$65-69$ & $13(6 \%)$ & $18(5 \%)$ & $5(6 \%)$ & $6(3 \%)$ \\
$70-79$ & $65(33 \%)$ & $103(27 \%)$ & $32(38 \%)$ & $71(37 \%)$ \\
$80-84$ & $44(22 \%)$ & $94(25 \%)$ & $13(15 \%)$ & $43(22 \%)$ \\
$85+$ & $43(22 \%)$ & $132(35 \%)$ & $15(18 \%)$ & $44(23 \%)$ \\
All ages & $198(100 \%)$ & $376(100 \%)$ & $84(100 \%)$ & $190(100 \%)$ \\
& & & & \\
\hline
\end{tabular}

Field loss was scored in relation to the severity indicated under section A.4, that is, $(a)$ nil, $(b)$ less than $10^{\circ},(c)$ contracted, $(d)$ central scotoma, $(e)$ hemianopia, $(f)$ good. Combinations of $(c)$ to $(e)$ were scored as $(b)$. The following criteria were used, therefore, in the reassessment:

$$
\begin{aligned}
& \text { acuity less than } 6 / 60 \text { (regardless of field) }=\text { blind } \\
& \text { field less than } 10 \% \text { (regardless of acuity) } \quad \text { = blind } \\
& \text { acuity equal or better than } 6 / 60 \text { but combination of field } \\
& \text { loss }(c, d, e) \\
& \text { other combinations } \\
& =\text { blind } \\
& =\text { PS. }
\end{aligned}
$$

The Avon population estimate for mid year 1985 based on the 1981 census was 942000 . In order to

\begin{tabular}{|c|c|c|c|c|c|c|}
\hline \multirow[t]{2}{*}{ Age } & \multicolumn{3}{|l|}{ Blind } & \multicolumn{3}{|c|}{ Partial sight } \\
\hline & Male & Female & Total & Male & Female & Total \\
\hline $0-4$ & $3 \cdot 5$ & - & $1 \cdot 8$ & - & - & - \\
\hline $5-14$ & $1 \cdot 7$ & 0.9 & $1 \cdot 3$ & - & 0.9 & 0.4 \\
\hline $15-19$ & - & $2 \cdot 6$ & $1 \cdot 3$ & - & - & - \\
\hline $20-29$ & $2 \cdot 0$ & $4 \cdot 0$ & $3 \cdot 0$ & $1 \cdot 3$ & $1 \cdot 3$ & $1 \cdot 3$ \\
\hline $30-39$ & $3 \cdot 0$ & $0 \cdot 8$ & $1 \cdot 9$ & $2 \cdot 3$ & $2 \cdot 3$ & $2 \cdot 3$ \\
\hline $40-49$ & $2 \cdot 7$ & $3 \cdot 7$ & $3 \cdot 2$ & $2 \cdot 7$ & $4 \cdot 6$ & $3 \cdot 6$ \\
\hline $50-59$ & $5 \cdot 0$ & $3 \cdot 9$ & $4 \cdot 4$ & $5 \cdot 0$ & $6 \cdot 8$ & 5.9 \\
\hline $60-64$ & $27 \cdot 5$ & $19 \cdot 5$ & $23 \cdot 3$ & $11 \cdot 8$ & $14 \cdot 2$ & $13 \cdot()$ \\
\hline $65-69$ & $32 \cdot 8$ & $38 \cdot 1$ & $35 \cdot 7$ & $12 \cdot 6$ & $12 \cdot 7$ & $12 \cdot 7$ \\
\hline $70-79$ & $110 \cdot 5$ & 118.9 & $115 \cdot 9$ & $54 \cdot 4$ & $82 \cdot()$ & $70 \cdot 8$ \\
\hline $80-84$ & $343 \cdot 8$ & $343 \cdot 1$ & $343 \cdot 3$ & $101 \cdot 6$ & $156 \cdot 9$ & $139 \cdot 3$ \\
\hline $85+$ & $716 \cdot 7$ & $647 \cdot 1$ & $662 \cdot 9$ & $250 \cdot()$ & $215 \cdot 7$ & $223 \cdot 5$ \\
\hline All ages & $21 \cdot 7$ & $38 \cdot 7$ & $30 \cdot 5$ & $9 \cdot 2$ & $19 \cdot 6$ & 14.5 \\
\hline
\end{tabular}
evaluate whether the newer ophthalmic techniques have influenced blind and PS registration, comparisons were made with the data published by Sorsby on patients registered more than 25 years ago.

Table 2 Incidence rates (per 100000 per year) of registrations according to age and sex
Table 3 Main causes of blindness and PS (total eyes after reclassification)

\begin{tabular}{lccc}
\hline & Blind & \multicolumn{1}{l}{ PS } & Total \\
\hline Aging macula & $565(49 \%)$ & $234(43 \%)$ & $799(47 \%)$ \\
Glaucoma & $176(15 \%)$ & $40(7 \%)$ & $216(13 \%)$ \\
Diabetes & $71(6 \%)$ & $51(9 \%)$ & $122(7 \%)$ \\
Myopia & $50(4 \%)$ & $41(8 \%)$ & $91(5 \%)$ \\
Cerebrovascular disease & $54(5 \%)$ & $31(6 \%)$ & $85(5 \%)$ \\
Optic atrophy & $51(4 \%)$ & $19(3 \%)$ & $70(4 \%)$ \\
Retinal vein occlusion & $34(3 \%)$ & $21(4 \%)$ & $55(3 \%)$ \\
Cataract (senile) & $24(2 \%)$ & $30(5 \%)$ & $54(3 \%)$ \\
Corneal disease (all causes) & $24(2 \%)$ & $14(3 \%)$ & $38(2 \%)$ \\
Retinitis pigmentosa & $20(2 \%)$ & $8(1 \%)$ & $28(2 \%)$ \\
Retinal detachment & $16(1 \%)$ & $10(2 \%)$ & $26(2 \%)$ \\
Congenital defects & & & \\
$\quad$ (including cataract) & $16(1 \%)$ & $8(1 \%)$ & $24(1 \%)$ \\
Amblyopia & $10(1 \%)$ & $7(1 \%)$ & $17(1 \%)$ \\
Others & $35(3 \%)$ & $32(6 \%)$ & $67(4 \%)$ \\
Total & $1146(10 \%)$ & $546(100 \%)$ & $1692(10) \%)$ \\
\end{tabular}

Cause not stated in four cases.

\section{Results}

There was a total of 848 forms of which $574(68 \%)$ were for blind registered patients and 274 (32\%) were for partially sighted. Thus the overall blindness rate was 30 per 100000 and the PS rate 15 per 100000 per annum. The numbers, age, sex, and registration rates of the study population are presented in Tables 1 and 2. The main causes of blindness and partial sight after reassessment are shown in Table 3 and are related to age in Tables 4 and 5. The degree of blindness according to acuity and field loss are shown in Tables 6 and 7. Some disagreement was observed between the original assessment and the reevaluation on visual grounds alone-Table 8 . Of the 496 patients re-evaluated as blind in both eyes 28 $(6 \%)$ were registered PS, and of the 130 patients considered PS in both eyes $26(20 \%)$ were registered blind. When one eye was reassessed as blind and one PS (221 cases), blind registration was recorded in 79 $(36 \%)$ rather than the theoretically correct PS, on the assumption that the patient should be registered according to the status of the better eye.

Different causes of blindness between the two eyes of the same patient were found in $15 \%$ of cases. The most common associations are listed in Table 9.

\section{Discussion}

\section{OVERALL FIGURES FOR BLINDNESS}

The incidence rates of blind registration have been based on the mid year estimates for 1985 from the 1981 census. For both males and females the incidence rate of blindness remains low until age 60 , after which there is a considerable increase, 
Table 4 Age distribution of main causes of disease leading to blindness and PS after reclassification (total eyes)

\begin{tabular}{|c|c|c|c|c|c|c|c|c|}
\hline Age & Aging macula & Glaucoma & Diabetes & Myopia & $\begin{array}{l}\text { Cerebro- } \\
\text { vascular }\end{array}$ & Optic atrophy & $\begin{array}{l}\text { Retinal } \\
\text { vein } \\
\text { occlusion }\end{array}$ & Cataract \\
\hline $0-4$ & 0 & 0 & 0 & 0 & 0 & $2(3 \%)$ & 0 & 0 \\
\hline $5-14$ & 0 & $2(1 \%)$ & 0 & 0 & 0 & 0 & $\mathbf{0}$ & 0 \\
\hline $15-19$ & 0 & $2(1 \%)$ & 0 & 0 & 0 & 0 & 0 & 0 \\
\hline $20-29$ & 0 & $2(1 \%)$ & $2(2 \%)$ & $1(1 \%)$ & 0 & $7(10 \%)$ & 0 & 0 \\
\hline $30-39$ & 0 & 0 & $4(3 \%)$ & $2(2 \%)$ & $2(2 \%)$ & 0 & 0 & 0 \\
\hline $40-49$ & 0 & $4(2 \%)$ & $10(8 \%)$ & 0 & $2(2 \%)$ & $2(3 \%)$ & 0 & 0 \\
\hline $50-59$ & $6(1 \%)$ & 0 & $8(7 \%)$ & $6(7 \%)$ & $2(2 \%)$ & $1(1 \%)$ & 0 & $2(4 \%)$ \\
\hline $60-64$ & $9(1 \%)$ & $4(2 \%)$ & $20(16 \%)$ & $2(13 \%)$ & $10(12 \%)$ & $5(7 \%)$ & $1(2 \%)$ & $1(2 \%)$ \\
\hline $65-69$ & $14(2 \%)$ & $9(4 \%)$ & $27(22 \%)$ & $4(4 \%)$ & $8(10 \%)$ & $7(10 \%)$ & $6(11 \%)$ & $2(4 \%)$ \\
\hline $70-79$ & $253(31 \%)$ & $80(37 \%)$ & $35(29 \%)$ & $29(32 \%)$ & $35(41 \%)$ & $17(24 \%)$ & $20(36 \%)$ & $14(26 \%)$ \\
\hline $80-84$ & $222(28 \%)$ & $52(24 \%)$ & $11(9 \%)$ & $18(20 \%)^{\prime}$ & $18(21 \%)$ & $12(18 \%)$ & $15(27 \%)$ & $13(24 \%)$ \\
\hline $85+$ & $295(37 \%)$ & $61(28 \%)$ & $5(4 \%)$ & $19(21 \%)$ & $8(10 \%)$ & $17(24 \%)$ & $13(24 \%)$ & $22(40 \%)$ \\
\hline All ages & $799(100 \%)$ & $216(100 \%)$ & $122(100 \%)$ & $91(100 \%)$ & $85(100 \%)$ & $70(100 \%)$ & $55(100 \%)$ & $54(100 \%)$ \\
\hline
\end{tabular}

especially after age 70 . Overall the incidence of blindness in females appears to be almost twice the rate in males, but in the extremely elderly ( 85 years and over) the rate for males is marginally higher (Table 2).

Compared with the figures published by Sorsby ${ }^{1}$ for 1961-2 the incidence of blindness in Avon for 1985 and 1986 is similar in the younger age groups $(0-30)$, but the numbers are small. Congenital and inherited disorders predominate, and the incidence of blindness is approximately $2 \cdot 5$ per 100000 . Thereafter the blindness rates quoted by Sorsby reach a higher level for each age group with the exception of males aged 60-64 (Table 10). The greatly reduced incidence of cataract registration could account for this trend.

The finding of a different cause of blindness in fellow eyes of $15 \%$ is considerably higher than the $6 \%$ noted by Sorsby. Uniocular diseases such as retinal detachment have a high incidence of different causes for the second eye, but not unexpectedly conditions producing bilateral disease such as aging macular degeneration have a low incidence of other causes of blindness in the fellow eye. The discrepancy between Sorsby's figures and ours may be partly explained by a lower incidence of cataract as a cause of registration and perhaps also by earlier detection of remediable forms of blindness, preserving useful function in one eye which later becomes affected by age related disease. The degree of blindness followed a similar pattern to what Sorsby found, though the groups were not strictly identical, as the present study did not include a category of $3 / 60$. In this study $11 \%$ had PL or NPL (Sorsby $=14 \%$ ) and $69 \%$ had count fingers or hand movements (Sorsby $=59 \%$ ).

Ghafour et al. ${ }^{3}$ published figures for blindness in the West of Scotland for the year 1980. Different age groupings were used from the present study, but the proportion of patients in the major diagnostic groups were similar. Aging macular degeneration was the

Table 5 Incidence rates of main causes of disease leading to blindness and PS per 100000 population per year (after reclassification)

\begin{tabular}{|c|c|c|c|c|c|c|c|c|}
\hline Age & Aging macula & Glaucoma & Diabetes & Myopia & $\begin{array}{l}\text { Cerebro- } \\
\text { vascular }\end{array}$ & Optic atrophy & $\begin{array}{l}\text { Retinal } \\
\text { vein } \\
\text { occlusion }\end{array}$ & Cataract \\
\hline $0-4$ & - & - & & - & - & 0.9 & - & - \\
\hline $0-14$ & - & 0.4 & & - & - & - & - & - \\
\hline $15-19$ & - & 0.7 & & - & - & - & - & - \\
\hline $20-29$ & - & 0.3 & 0.3 & 0.2 & - & $1 \cdot 2$ & - & - \\
\hline $30-39$ & - & - & 0.8 & 0.4 & 0.4 & - & - & - \\
\hline $40-49$ & - & 0.9 & $2 \cdot 3$ & - & 0.5 & 0.5 & - & - \\
\hline $50-59$ & $1 \cdot 5$ & - & $2 \cdot 0$ & $1 \cdot 5$ & $0 \cdot 5$ & $0 \cdot 2$ & - & 0.5 \\
\hline $60-64$ & $4 \cdot 2$ & 1.9 & $9 \cdot 3$ & $5 \cdot 6$ & $4 \cdot 7$ & $2 \cdot 3$ & $0 \cdot 5$ & 0.5 \\
\hline $65-69$ & $8 \cdot 1$ & $5 \cdot 2$ & $15 \cdot 6$ & $2 \cdot 3$ & $4 \cdot 6$ & $4 \cdot 0$ & $3 \cdot 5$ & $1 \cdot 2$ \\
\hline $70-79$ & $87 \cdot 0$ & $27 \cdot 5$ & $12 \cdot 0$ & $10 \cdot 0$ & $12 \cdot 0$ & $5 \cdot 8$ & $6 \cdot 9$ & $4 \cdot 8$ \\
\hline $80-84$ & $276 \cdot 1$ & $64 \cdot 7$ & $13 \cdot 7$ & $22 \cdot 4$ & $22 \cdot 4$ & $14 \cdot 9$ & $18 \cdot 7$ & $16 \cdot 2$ \\
\hline $85+$ & 558.7 & $115 \cdot 5$ & 9.5 & $36 \cdot 0$ & $15 \cdot 2$ & $32 \cdot 2$ & $24 \cdot 6$ & $41 \cdot 7$ \\
\hline All ages & $21 \cdot 2$ & $5 \cdot 7$ & $3 \cdot 2$ & $2 \cdot 4$ & $2 \cdot 3$ & $1 \cdot 9$ & $1 \cdot 5$ & 1.4 \\
\hline
\end{tabular}


Table 6 Visual acuity by eyes (after reclassification): incomplete information for seven registrations

\begin{tabular}{lccc}
\hline Acuity & Blind & Partial sight & Total \\
\hline NPL & $72(6 \%)$ & $18(3 \%)$ & $90(5 \%)$ \\
PL & $61(5 \%)$ & $15(3 \%)$ & $76(5 \%)$ \\
HM & $158(14 \%)$ & $44(8 \%)$ & $202(12 \%)$ \\
CF & $631(55 \%)$ & $97(18 \%)$ & $728(43 \%)$ \\
$6 / 60$ & $104(9 \%)$ & $100(18 \%)$ & $204(12 \%)$ \\
$6 / 36$ & $38(3 \%)$ & $116(21 \%)$ & $154(9 \%)$ \\
$6 / 24$ & $15(1 \%)$ & $59(11 \%)$ & $74(4 \%)$ \\
$6 / 18$ & $19(2 \%)$ & $55(10 \%)$ & $74(4 \%)$ \\
$6 / 12$ & $18(2 \%)$ & $21(4 \%)$ & $39(2 \%)$ \\
$>6 / 12$ & $27(2 \%)$ & $18(3 \%)$ & $45(3 \%)$ \\
Total & $1143(100 \%)$ & $543(100 \%)$ & $1686(100 \%)$ \\
\hline
\end{tabular}

principal cause but formed $18 \%$ less of the total in comparison with this study. Cataract was higher by $8 \%$, but glaucoma, diabetes, and optic atrophy were not significantly different.

OVERALL FIGURES FOR PARTIAL SIGHT

The causes of partial sight closely followed those of full registration but were approximately half as common, namely, $32 \%$ of the total. This may be a reflection of the limited social service benefits available to patients on the partially sighted register, which could also explain the relatively high number of registrations classified as blind which theoretically should have been PS. PS registration for glaucoma was proportionally less than average $(19 \%$ of glaucoma registrations), whereas diabetes $(41 \%)$, myopia $(45 \%)$, and cataract $(55 \%)$ were more than average. Ghafour et al. noted similar patterns, though PS registration was $45 \%$ of the total compared with $32 \%$ in this study.

A DHSS report published in $1979^{4}$ noted a steady increase in PS registrations between 1969 and 1976. Unfortunately rates per 100000 were not quoted except for children, and the present study contains very few registrations of young people. 'Macular lesion', cataract, and glaucoma accounted for $80 \%$ of the PS registrations listed but for only approximately $63 \%$ in this study.

Table 7 Field of vision by eyes (after reclassification): incomplete information for 15 registrations

\begin{tabular}{lccc}
\hline Field & Blind & Partial sight & Total \\
\hline (a) Nil & $130(11 \%)$ & $42(8 \%)$ & $172(10 \%)$ \\
(b) Less $10^{\circ}$ & $167(15 \%)$ & $60(11 \%)$ & $227(14 \%)$ \\
(c) Contracted & $135(12 \%)$ & $75(14 \%)$ & $210) 13 \%)$ \\
(d) Central scotoma & $648(57 \%)$ & $267(50 \%)$ & $915(55 \%)$ \\
(e) Hemianopia & $38(3 \%)$ & $31(6 \%)$ & $69(4 \%)$ \\
() Good & $22(2 \%)$ & $61(11 \%)$ & $83(5 \%)$ \\
Total & $1140(100 \%)$ & $536(100 \%)$ & $1676(100 \%)$ \\
\hline
\end{tabular}

Combinations of $(c),(d)$, or $(e)$ were scored as $(b)$.
Table 8 Registration status compared with re-evaluation status

\begin{tabular}{llr}
\hline Re-evaluation & \multicolumn{2}{l}{ Registered } \\
\cline { 2 - 3 } & Blind & PS \\
\hline Both blind & 468 & 28 \\
One blind/one PS & 79 & 142 \\
Both PS & 26 & 104 \\
\hline
\end{tabular}

\section{SPECIFIC CONDITIONS}

We have compared the present figures for the leading causes of blind registration with those of Sorsby in those age groups with a high incidence (Fig. 1 and Table 11).

\section{DIABETIC RETINOPATHY}

In the past 15 years xenon and laser photocoagulation have become established as beneficial treatment for the sight threatening forms of retinopathy, namely, maculopathy and proliferative retinopathy. The current study suggests that there has been no reduction in the total registrations per 100000 (Fig. 1a) in spite of an active therapeutic approach to retinopathy within the area of Avon. There has been an increase of 3.6 per 100000 in the $60-69$ year age group and a decrease of 4.9 in patients aged 70 or over.

It has been found that the prevalence of insulin dependent diabetics in childhood has risen greatly in the past 30 years, perhaps as much as doubling every decade. $^{56}$ This, together with the estimate that sight threatening retinopathy is three times more common in insulin than non-insulin dependent diabetics, would suggest that the overall incidence of serious retinopathy is much higher than 25 years ago. The unchanged total diabetic registration incidence now compared with Sorsby's would indicăte an encourag-

Table 9 Numbers of eyes with different causes of blindness in fellow eyes

\begin{tabular}{|c|c|c|}
\hline & Total & Common combinations \\
\hline $\begin{array}{l}\text { Aging macular } \\
\text { disease }\end{array}$ & 49 eyes $(6 \%)$ & $\begin{array}{l}\text { Cataract in } 9 \text { eyes } \\
\text { Retinal detachment } 5 \text { eyes } \\
\text { Amblyopia } 5 \text { eyes }\end{array}$ \\
\hline $\begin{array}{l}\text { Venous } \\
\text { occlusion }\end{array}$ & 31 eyes $(56 \%)$ & $\begin{array}{l}\text { AMD } 7 \text { eyes } \\
\text { Glaucoma } 6 \text { eyes } \\
\text { Amblyopia } 6 \text { eyes } \\
\text { Cataract } 5 \text { eyes }\end{array}$ \\
\hline Cataract & 27 eyes $(50 \%)$ & $\begin{array}{l}\text { AMD } 9 \text { eyes } \\
\text { Venous occlusion } 5 \text { eyes } \\
\text { Retinal detachment } 5 \text { eyes }\end{array}$ \\
\hline Glaucoma & 26 eyes $(12 \%)$ & $\begin{array}{l}\text { Venous occlusion } 7 \text { eyes } \\
\text { AMD } 5 \text { eyes }\end{array}$ \\
\hline $\begin{array}{l}\text { Retinal } \\
\text { detachment }\end{array}$ & 23 eyes $(88 \%)$ & $\begin{array}{l}\text { Myopia } 9 \text { eyes } \\
\text { AMD } 5 \text { eyes } \\
\text { Venous occlusion } 5 \text { eyes }\end{array}$ \\
\hline Amblyopia & 17 eyes $(100 \%)$ & $\begin{array}{l}\text { Venous occlusion } 6 \text { eyes } \\
\text { AMD } 5 \text { eyes }\end{array}$ \\
\hline
\end{tabular}


Table 10 Blind registration rates per 100000 population for Sorsby (1959-60) and Avon (1985-6)

\begin{tabular}{|c|c|c|c|c|}
\hline \multirow[t]{2}{*}{ Age } & \multicolumn{2}{|l|}{ Males } & \multicolumn{2}{|c|}{ Females } \\
\hline & Sorsby & Avon study & Sorsby & Avon study \\
\hline $40-49$ & $5 \cdot 1$ & $2 \cdot 7$ & $4 \cdot 4$ & 3.7 \\
\hline $50-59$ & $10 \cdot 0$ & $5 \cdot 0$ & $11 \cdot 4$ & 3.9 \\
\hline $60-64$ & $21 \cdot 3$ & $27 \cdot 5$ & $26 \cdot 6$ & $19 \cdot 5$ \\
\hline $65-69$ & $51 \cdot 6$ & $32 \cdot 8$ & $51 \cdot 5$ & $38 \cdot 1$ \\
\hline $70+$ & $208 \cdot 7$ & 195.9 & $237 \cdot 8$ & $170 \cdot 4$ \\
\hline
\end{tabular}

ing trend, suggesting that photocoagulation has been effective in preventing blindness in many diabetics. Whether the prevalence of non-insulin diabetes is increasing is unknown.

Although the rate of blind registration for people of working age is small, there is still a significant number of patients in middle life who require registration (Table 4). Sorsby noted a steady increase within these age groups between 1948 to 1960, but encouragingly this trend would seem to have reversed. One aspect of blindness which is not possible to ascertain from the comparative data is change in degree of blindness over the years. It is possible that navigational vision is preserved in a large proportion of diabetics which would have deteriorated to no useful vision prior to photocoagulation! In this series 122 eyes were registered as showing diabetic retinopathy. Of these, $27(22 \%)$ had no useful vision, that is, hand movements or worse, $57(47 \%)$ were count fingers, and $38(31 \%)$ were $6 / 60$ or better.

\section{AGING MACULAR DEGENERATION}

The proportion of blind registrations due to aging macular degeneration (AMD) appears to be increasing (Sorsby 1955-60: 26.9\%; Ghafour 1980: $29 \cdot 8 \%$; present study $1985-6: 49 \%$ ). As the majority of cases are not treatable, it might be expected that this percentage would increase as correctable forms of blindness such as cataract are prevented. Our figures may perhaps support this, but there is a very large increase in the rate per 100000 both in the total

\section{RATES OF BLIND REGISTRATION}

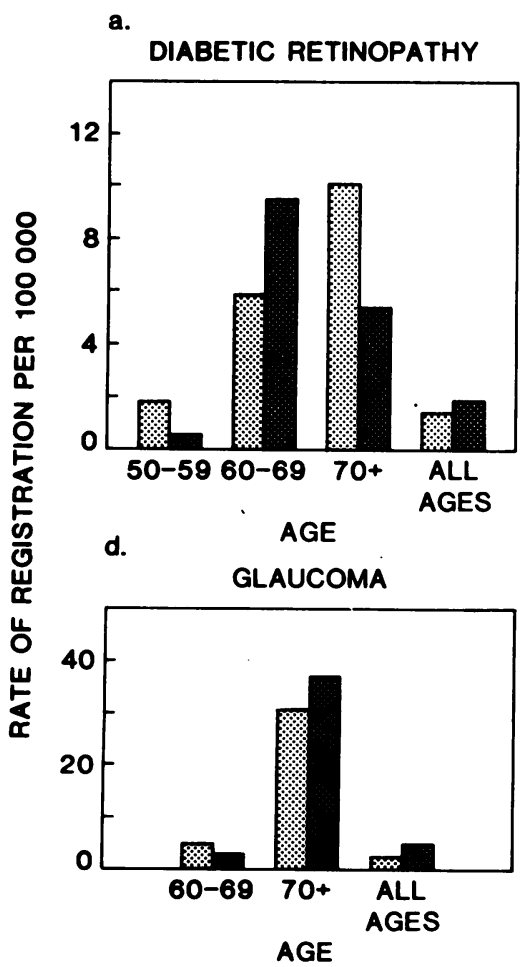

\section{b. AGING MACULAR DEGENERATION}

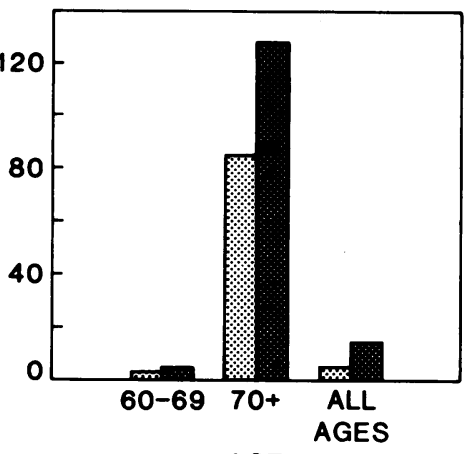

e.

AGE

MYOPIA

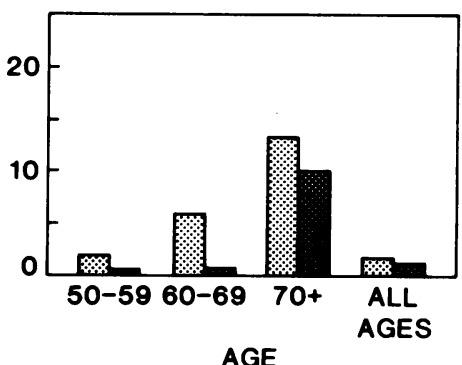

c.

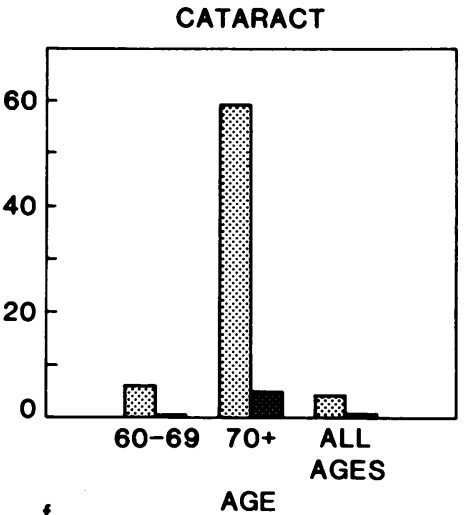

f.

OPTIC ATROPHY

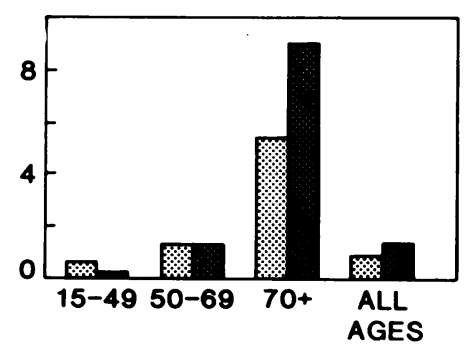

AGE

Fig. 1 Comparison of blindness rates per 100000 population of Sorsby (1959-60) and Avon (1985-6): age groups as in Sorsby. ${ }^{12}$ 
Table 11 Rates of blind registration per 100000 population for common disorders: comparison of Sorsby $1959-60$ with Avon 1985-6 (age groups as in Sorsby)

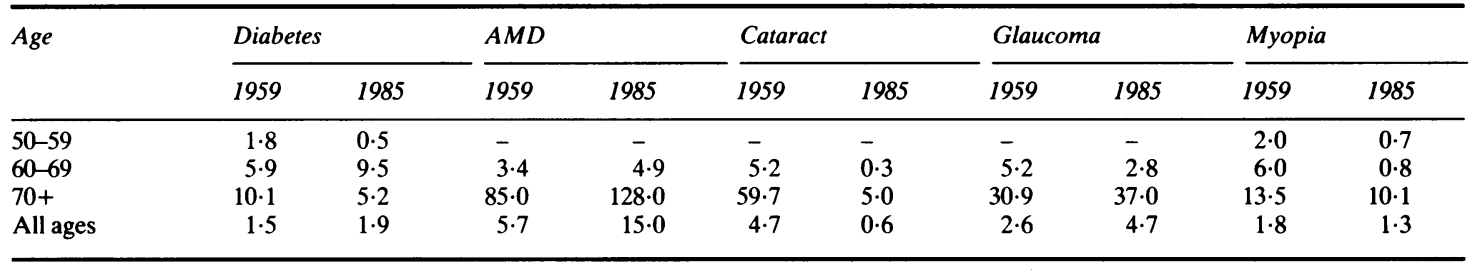

number of registrations and for patients over 70 which cannot all be accounted for by redistribution from other causes (Fig. 1b). Increased social service support such as home help and mobility training may explain this increase.

One consultant subdivided all AMD registrations into disciform and atrophic types. From a total of 128 eyes registered in this way $35(27 \%)$ were disciform lesions and 93 (73\%) were dry geographic atrophy. Of the patients with disciform lesions $22(63 \%)$ were blind and $13(37 \%)$ PS and of patients with atrophic lesions $80(86 \%)$ were blind and $13(14 \%)$ PS. When disciform lesions were compared with geographic atrophy with regard to the degree of blindness there was no difference between the two groups. This suggests that severe macular atrophy is three times more common than disciform degeneration and produces an equal degree of visual loss. Laser photocoagulation of disciform degeneration can therefore be expected to have only a limited effect on figures for blindness from aging degeneration.

\section{CAT A RACT}

Cataract is the one diagnostic category to have shown a marked decrease over the years (Fig. 1c). The trend outlined by Sorsby has continued, so that for the 6069 year age group the rates per 100000 were 11.6 in $1984,5 \cdot 4$ in 1960 , and 0.3 currently. In the $70+$ age group the comparable figures were $82 \cdot 6,57 \cdot 6$, and $5 \cdot 0$. Factors which have contributed to this must include improved microsurgical techniques and the introduction of intraocular lenses. The latter measure has allowed much earlier intervention in the 'worse eye' before severe loss of vision bilaterally, which was necessary for aphakic spectacle wear.

\section{G L A U COMA}

In the 60-69 year age group the downward trend in registrations has continued: $7 \cdot 2$ in $1949,4.9$ in 1960 , and 2.8 currently. However, in spite of a greater variety of topical medications and the introduction of safer glaucoma surgery the overall figures, .particularly in the $70+$ age group, show there is a modest increase in the rate of registration (Fig. 1d). The great majority of registrations are in the older people and there has been no marked reduction which might have been expected with the better therapeutic methods now available. This could be explained by the fact that glaucoma is a chronic disease in many patients, with a better outlook if treated early. The newer treatments would therefore not yet be reflected in the incidence figures, on the assumption that several years elapse between diagnosis and registration. More time is needed for the full assessment of beta blockers and laser trabeculoplasty.

\section{MYOPIA}

Between 1948 and 1960 Sorsby noted a modest decrease in the rate of registration for patients less than 50 years, little change for those aged 50-69, and a slight increase for those aged $70+$. Since then there would seem to have been a further decrease in all age groups, with the bulk of the registrations occurring at 70 and over (Fig. 1e), indicating blindness from myopia is related to age.

\section{OPTIC ATROPHY}

The number of patients in the present series is small but there appears to have been no significant change over the years (Fig. 1f). It may be assumed that the underlying causes such as generalised vascular disease and systemic hypertension are as common in the population as previously.

\section{OTHER CONDITIONS}

In terms of frequency of various causes of registration the 'league tables' have shown some changes in the middle order compared with Sorsby's figures. Hypertension has disappeared as a cause of blindness, but it is possible that venous occlusions may have been included in this diagnosis in the past. Iritis and retinopathy of prematurity are also less frequent causes than previously.

Retinal detachment and cerebrovascular disease, especially the latter, form a higher proportion of registrations than 25 years ago, and the figures for corneal disorders are approximately unchanged with $2 \%$ of the total. $66 \%$ of registrations are from retinal disorders and a further $17 \%$ from optic nerve disorders. 
The interpretation of blind registration figures has to be cautious. The present study is over two years, with the great majority of the BD8s completed by 10 ophthalmologists. There is no obvious reason to think that Avon is not representative of the UK in general, both in terms of the resident population or of the type of medical care, but the accuracy of such a study depends on the quality of form filling. It is therefore unlikely that any figures are completely reliable, as observer variations occur. There is also some pressure to register blind rather than PS for borderline cases, as the benefits from the social services are considerably greater. It could be argued that help from the social services may be better than 25 years ago and that this would lead to an increase in the number of registrations. This could account for the larger registration rate for AMD or glaucoma, if it used to be thought that services previously were not all that helpful. This is unlikely to be a major factor, as some conditions which are largely beyond help by current medical therapy have shown no such trendfor example, optic atrophy remains static and myopia shows a decreased incidence. Care is also required in the interpretation of registration figures with regard to the prevalence of blindness in the population in general. Probably many more patients are eligible for registration than are actually recorded but are either unwilling or unlikely to be helped by registration.

By extrapolating Sorsby's blindness rates of 1959-
60 and applying them to Avon in 1985-6 an extra 28 males and 74 females would have been registered blind per annum - that is, the 1985-6 rate is down $27 \%$ for males and $39 \%$ for females. The great majority of this reduction is due to the fall in cataract registrations.

The authors thank Mrs Linda Clayton for typing the manuscript and staff of DHSS, Bristol, for photocopies of the registration forms.

\section{References}

1 Sorsby A. The incidence and causes of blindness in England and Wales 1948-1962. Reports on Public Health and Medical Subjects, No. 114. London: HMSO, 1966.

2 Sorsby A. The incidence and causes of blindness in England and Wales 1963-1968. Reports on Public Health and Medical Subjects, No. 128. London: HMSO, 1972.

3 Ghafour IM, Allen D, Foulds WS. Common causes of blindness and visual handicap in the West of Scotland. Br J Ophthalmol 1983; 67: 209-13.

4 Department of Health and Social Services. Blindness and partial sight in England 1969-1976. Reports on Public Health and Medical Subjects, No. 129. London: HMSO, 1979.

5 Calnan M, Peckham CS. Incidence of insulin dependent diabetes in the first sixteen years of life. Lancet 1977; i: 589-90.

6 Stewart-Brown S, Haslum M, Butler N. Evidence for increasing prevalence of diabetes mellitus in childhood. $\mathrm{Br}$ Med $J$ 1983; 286: 1855-7.

7 Grey RHB, Malcolm N, O'Reilly D, Morris A. Ophthalmic survey of a diabetic clinic. I. Ocular findings. Br J Ophthalmol 1986; 70: 797-803.

Accepted for publication 25 February 1988. 